\title{
Acerca de los imaginarios de ciudadanía de los estudiantes de primer semestre de Uniminuto Sede Principal ${ }^{1}$
}

\author{
Estudio de caso Santa fe de Bogotá
}

\begin{abstract}
About the citizenship imaginaries of the first semester students of Uniminuto headquarters
\end{abstract}

Jenny Consuelo Mahecha Escobar

Elquin Eduar Mejía Loaiza

Mahecha E, Jenny. Mejía L. Elquin miradas $\mathrm{N}^{\circ} 1-2018$ ISSN digital $\mathrm{N}^{\circ} 2539-3812$ Págs 28 - 52

Recepción: Agosto 22 de 2017

Aprobación: Abril 9 de 2018

Publicación: Junio 29 de 2018

\section{Resumen}

Este artículo presenta la investigación Acerca de los imaginarios de ciudadanía de los estudiantes de primer semestre de Uniminuto Sede Principal. El proyecto se orientó a lograr un acercamiento a los imaginarios de ciudadanía que sus estudiantes de primer semestre tienen y a determinar las posibles incidencias de dichos imaginarios en su sentido de participación. A la luz de Martha Nussbaum (2014), con su libro Emociones Politicas ¿Por qué el amor es importante para la justicia? y del soporte teórico de Armando Silva, se logró vislumbrar un panorama más claro sobre la concepción de ciudadanía desde la emocionalidad del ser humano y sobre los imaginarios y sus configuraciones en los diferentes escenarios sociales.

Esta investigación se ubica dentro del paradigma cualitativo, desde un enfoque hermenéutico-interpretativo, en un estudio de caso en el que se aplicó la herramienta del taller pedagógico en los diferentes formatos. Los resultados permitieron determinar que los imaginarios de ciudadanía más representativos para los jóvenes estudiantes de primer

1 Este artículo es producto de la tesis de Maestría en Comunicación Educativa del convenio UTP-Uniminuto (Bogotá), titulada Acerca de los imaginarios de ciudadanía de los estudiantes de primer semestre de Uniminuto sede principal. Elquin Eduar Mejía Loaiza (elmejilo@yahoo.com) y Jenny Consuelo Mahecha Escobar (jmahecha@uniminuto.edu) son profesores de la asignatura Proyecto de Vida de Uniminuto, sede principal, egresados de la maestría en Comunicación Educativa de la UTP. 
semestre de Uniminuto son el respeto, la justicia, la empatía, el altruismo, el idealismo, la sinergia colectiva, el sentido de familia y el sentido de vida, en cuanto acuerdos y valores humanos y sociales que motivan su sentido de participación.

Palabras clave: imaginarios urbanos, ciudadanía, participación, emociones políticas, estudiantes universitarios y educomunicación.

\section{Abstract:}

This paper presents the research about the citizenship imaginaries from first-semester students of Uniminuto Headquarters. This project was directed to achieve an approach to citizenship imaginaries that its first semester college students have; bringing to light possible incidences from such imaginaries in their participation concepts. In the light of Martha Nussbaum (2014) book: Emotions Politics, Why is love important for justice?

Also reflecting on Armando Silva researches as theoretical reference, it was possible to glimpse a clearer panorama on the conception of citizenship from the emotionality of the human being and on the imaginaries about their configurations in different social scenarios.

This research is located within the qualitative paradigm, from a hermeneuticinterpretative approach, in a case study in which the tool of the pedagogical workshop was applied in different formats. The results allowed determining that the most representative imaginaries of citizenship for young students of the first semester of Uniminuto are: respect, justice, empathy, altruism, idealism, collective synergy, sense of family and sense of life, concerning about agreements on human and social values which motivate their sense of participation.

Keywords: imaginaries, citizenship, participation, political emotions, university students, educommunication.

\section{Introducción}

Este artículo presenta la investigación Acerca de los imaginarios de ciudadanía de los estudiantes de primer semestre de Uniminuto Sede Principal, desarrollada en el marco de la Maestría en Comunicación Educativa, de la Universidad Tecnológica de Pereira, trabajo de grado dirigido y asesorado por la docente investigadora Catalina Campuzano. Se presenta un ejercicio académico que nace de la pregunta referida a ¿qué imaginarios de ciudadanía tienen los estudiantes de primer semestre de Uniminuto Sede Principal y qué implicaciones tienen dichos imaginarios en su sentido de participación?, con lo que se busca un acercamiento a las posibles concepciones de lo que para estos estudiantes de primer semestre en el contexto universitario implica el ejercicio ciudadano, todo lo anterior en una aproximación a la interpretación de su emocionalidad política, expresada a través de diversos lenguajes, reconociendo la importancia de la comunicación como elemento mediador en el accionar ciudadano.

En este artículo se relaciona lo más esencial del marco teórico, el cual se construyó a partir de tres categorías: imaginarios, ciudadanía y participación, a la luz de los autores Martha Nussbaum y Armando Silva, quienes se han preocupado de manera especial por estos temas de construcción 
social. Con ellos se logró establecer un diálogo teórico que abrió camino al encuentro con el sentir ciudadano y, de manera especial, con la emocionalidad política de los estudiantes de primer semestre de Uniminuto Sede Principal.

Se presentan elementos importantes en términos metodológicos en esta investigación cualitativa, que se apoyó principalmente en el taller pedagógico en diferentes formatos y en el análisis crítico del discurso, para ir al encuentro con el sentido social de estos jóvenes estudiantes, quienes a través de ejercicios educomunicativos dejaron ver su sentir político y sus imaginarios de ciudadanía. De otro modo, se habla de la sistematización y análisis de la información, fases en las que jugó un papel fundamental la comunicación, pues permitió, a través de diversos lenguajes, relacionar, articular e interpretar la información.

En la parte final de este artículo se presentan los resultados de la investigación. Allí se muestran con claridad los imaginarios de ciudadanía de los jóvenes estudiantes, sus sentires más representativos con relación a un ideal de construcción social. Se presentan además las conclusiones y los aportes de este estudio a la educomunicación.

\section{Planteamiento del problema}

La Uniminuto, en calidad de institución de educación superior que cuenta con espacios para la formación humana, ofrece el curso Proyecto de Vida, espacio en el que los autores de este documento desarrollan su labor docente. Con el curso se busca abrir espacios para el reconocimiento del "ser multidimensional", del "ser social" y del sentido vocacional y misional; particularmente, en el espacio para el "ser social" es donde se da una conexión con el tema de ciudadanía. En este sentido, es ineludible que, a partir de la experiencia docente, en este curso se presenten inquietudes a propósito de los imaginarios que recrean, teniendo en cuenta que, en las actividades, talleres, ejercicios, etc., se evidencia desconexión, apatía, confusión y desinterés por parte de los estudiantes frente a lo que concierne a la ciudadanía. Además, sus emociones dan cuenta de sus sentires en relación con las buenas y malas prácticas, pero desde una mirada muy tradicional, dejando ver que su concepción de ciudadanía es limitada por un modelo más liberal.

Por lo anterior, se demanda un trabajo importante orientado a lograr un acercamiento a su sentir más profundo sobre los imaginarios de ciudadanía, pero, esta vez, desde su emocionalidad política, haciendo uso de otros lenguajes mucho más subjetivos, como es el caso de sus emociones. De otro modo y trascendiendo los escenarios sociales en Colombia y en el mundo, se ve con preocupación que aspectos como la acción y la sinergia colectiva, el sentido de pertenencia, el reconocimiento de lo público, la convivencia, el respeto y la participación, entre otros, parecen no fortalecerse y, más bien, diluirse en medio de la indiferencia y el individualismo. De este fenómeno dan cuenta los altos índices de corrupción en Colombia, que han desdibujado el sentido del ejercicio de la política, pues se han roto lazos de confianza que no se reconstruyen fácilmente. Dichos actos han permeado además todos los ámbitos de la sociedad: desde las cámaras de representación, los entes administrativos, el sector de la salud, el sistema financiero, los medios de 
comunicación, los organismos de justicia, hasta los escenarios ideológicos y religiosos, lo que lleva, a veces, a encontrarse con un panorama poco alentador.

Uniminuto tiene como uno de sus grandes propósitos formar excelentes seres humanos, profesionales integrales capaces de cambiar sus condiciones de vida, motores de transformación, en fin, ciudadanos con sentido humano y social. Todo esto hace que se genere la necesidad de trabajar por una sociedad mucho más conectada con los valores ciudadanos, por lo que aparece el siguiente planteamiento: ¿Qué imaginarios de ciudadanía tienen los estudiantes de primer semestre de Uniminuto Sede Principal y qué implicaciones tienen dichos imaginarios en su sentido de participación?

\section{Marco conceptual}

¿Por qué el amor es importante para la justicia? Esta pregunta, que Nussbaum (2014) se hace en su libro sobre las emociones políticas y que plasma como parte del título, hace que se piense en la necesidad de un ejercicio ciudadano mucho más humano y consciente. En este sentido, Nussbaum emprende un análisis de la condición humana desde las emociones, en cuanto sentimientos que se generan en diversas circunstancias del accionar cotidiano y que juegan un papel importante en las decisiones de los ciudadanos. Esta amplia visión de la ciudadanía abre caminos para esta investigación en términos teóricos, en las categorías de ciudadanía y participación, y facilita un diálogo hacia la construcción de nuevos contenidos que ayudan a ver estos temas desde otras perspectivas.
Por su parte, Armando Silva ofrece valiosos aportes sobre los imaginarios y sus configuraciones en los diferentes escenarios sociales, aspectos que le dan sentido a este proyecto de investigación. Silva (2012), para quien lo imaginario no es ni mentira ni secreto, pues las personas lo viven constantemente, ofrece bases importantes para la producción teórica de la categoría imaginarios.

Con sus obras, Nussbaum y Silva ayudan a dilucidar esta propuesta en términos teóricos $\mathrm{y}$ orientan una ruta hacia el encuentro con los imaginarios de ciudadanía de los estudiantes de primer semestre de Uniminuto Sede Principal.

\section{Imaginarios}

Para Silva (2006), los imaginarios no aparecen de la nada, sino que se constituyen a través de la historia y están en todo lo que se hace a diario. Es así que el sentido del mundo está y se halla en todo lo que hacemos, en esas experiencias de vida que transforman más allá de la norma y el deber ser, que irrumpen y se legitiman desde los colectivos desde donde logramos trascender, reproducir y gestionar nuevas historias que nos configuren. En este sentido, se hace referencia a un mundo complejo y deambulante, que pareciera cambiar con la rapidez del tiempo, pero que, a la vez, se detiene y evoluciona lentamente por medio de esos nuevos significados imaginados, que terminarán siendo parte de los relatos que seguramente otros leerán y contarán. Es importante legitimar estos imaginarios y lograr su reconocimiento en la consolidación de las nuevas sociedades para tener un referente mucho más cercano a las realidades sociales y a las transformaciones culturales. 
Hacer visibles estos espacios es habilitar la propia existencia humana y las profundas relaciones que se dan en ella: la vida y la muerte, el amor y el odio, es decir, nuestras acciones diarias.

Para Silva (2012), es necesario ver los imaginarios desde tres tipos de inscriptores: «el imaginario como construcción o marca psíquica; el imaginario como construcción social de la realidad, y el imaginario en cuanto modo que permite la expresión material por alguna técnica» (p.36). Es decir, el imaginario ha de trascender el pensamiento; ese yo interior ha de tocar las fibras sociales, irrumpiendo en lo que conocemos como real y, por ende, habrá de generar hechos y acciones visibles que permitan nuevas lecturas del actuar social. En busca de ampliar la reflexión en su obra, Silva define los imaginarios como «procesos psíquicos perceptivos, motivados por el deseo, que operan como modos de aprender el mundo, y generan visiones y acciones colectivas» (p. 39).

Hablar de imaginarios es hablar entonces de esas construcciones desde el pensamiento, desde la emoción, construcciones indeterminadas, verdades cambiantes, significaciones y representaciones, no solo desde lo vivido sino desde lo sentido, lo no necesariamente experimentado de lo que resultan diversas formas de vivir, de relacionarse con los otros, con el entorno, que cobran fuerza y duran en el tiempo a pesar de su alto grado de complejidad para interpretarse y materializarse.

\section{Ciudadanía}

De acuerdo con Nussbaum (2014), en todas las sociedades, la ira, la simpatía, el asco, la envidia, la culpa y la aflicción están presentes siempre y todas las emociones están dirigidas hacia los rasgos geográficos de un país; es decir, todo su sentir se orienta en su sentido de pertenencia con sus territorios y con sus culturas y pueden hallar motivaciones grandes en términos de su ejercicio ciudadano.

En su libro Emociones Politicas ¿Por qué el amor es importante para la justicia?, Nussbaum hace un análisis de la condición humana desde las emociones, esos sentimientos que se generan en diversas circunstancias del accionar cotidiano y que juegan un papel importante en las decisiones de los ciudadanos y en el reconocimiento, no solamente del otro, sino también de los otros, en una mirada más amplia a todos los seres vivos. Para ella, los ciudadanos deben trascender sus fronteras en todo sentido e importarle lo que pasa en naciones distintas a la propia. Nussbaum (2014) también advierte que los ciudadanos deben reconocer que las naciones con mayor posibilidad de desarrollo económico deben ayudar a aquellas que tienen menores posibilidades, y sostiene además que los animales se preocupan y sienten la compasión y la pérdida, en algunos casos más que los humanos. Con esto, la autora hace un llamado a la reflexión en el actuar humano, que poco se compadece frente a la adversidad del otro y que busca más bien imponerse por encima de él o de aquellos de sus círculos cercanos.

Nussbaum también habla de la compasión, a la que entiende como una de las emociones que reacciona a los infortunios de los otros. $\mathrm{Al}$ respecto, dice que tiene tres elementos definitorios: que el sufrimiento del otro es grave, esa persona no es culpable de su propio sufrimiento y que a cualquiera puede pasarle. El asco representa al otro como 
un animal vil y no hay reconocimiento por otras especies. Producto de nuestra herencia animal, es la estrechez de nuestra compasión, pues está orientada a nuestros grupos primarios y no trasciende a otros. En este sentido, Alberto Prada (2011) refiere la autora y permite ver que la ciudadanía en nuestra sociedad ha sido vista desde una forma muy convencional, en la que prima la linealidad. Quizá esta estrechez - de la que hablamos anteriormente-, nos alcanza y no nos permite trascender en otras miradas.

En un sentido mucho más pedagógico, para Nussbaum (2014), el papel que debe asumir la formación debe premiar una educación centrada en la argumentación, en la valoración de la dignidad humana, en la participación colectiva y en la importancia de denunciar todo tipo de sometimiento y de humillación. Solo así la formación ciudadana entenderá cuál es la postura y el carácter que debe asumir frente a aquellos que pasan por alto el respeto a los derechos humanos y su importancia como requisitos mínimos para hablar de dignidad humana. La ciudadanía tiene el reto de formar en vínculos con lazos de mutuo reconocimiento y mutua preocupación:

\section{Una educación es} verdaderamente 'adecuada para la libertad' sólo si produce ciudadanos libres, ciudadanos libres no debido a la riqueza o al nacimiento, sino porque se saben dueños de sus propias mentes. Hombres y mujeres, nacidos esclavos y nacidos libres, ricos y pobres, se han mirado a sí mismos y han desarrollado la habilidad de distinguir entre hábito $\mathrm{y}$ convención, y lo que pueden defender con argumentos. Son dueños de su propio pensamiento y voz, y esto le confiere una dignidad que está mucho más allá de la dignidad exterior de clase o rango (Nussbaum, 2014, p. 320)

Los aportes teóricos de Martha Nussbaum sientan bases importantes en esta investigación, toda vez que su mirada amplia sobre la ciudadanía y su propuesta particular de ver las prácticas y acciones sociales a través de las emociones, y no desde una perspectiva tradicional, vislumbran un horizonte en el propósito de este trabajo, que busca un acercamiento a los imaginarios de ciudadanía de los estudiantes de primer semestre en Uniminuto Sede Principal.

\section{Participación}

Realizar el ejercicio del reconocimiento de este escenario desde la postura de Nussbaum es hablar de toda una apuesta ética, en contraposición a lo que ella reconoce como la crisis silenciosa, generada por el alto grado de deshumanización al que se ven enfrentados los ciudadanos globales, que están en el día de hoy más interesados por alcanzar grandes estándares de productividad que en pensar en las necesidades sociales latentes en el mundo de hoy. Es por esto que advierte que un ciudadano que participe y se desempeñe en el mundo, debe hacerlo con sensibilidad y capacidad de comprensión (Nussbaum, 2014).

Desde Prada, la mirada de Nussbaum, si se quiere solidificar la democracia y una búsqueda permanente de justicia que 
considere el bien común, el ciudadano debe poder dar razón de aquello en lo que cree, por lo que se inclina, lo que verdaderamente le importa, y la relación que estas perspectivas tienen consigo mismo y con los demás. No cabe duda de que la posición que en la lectura que Prada hace de Nussbaum asume respecto de la formación ciudadana tiene como marco una democracia liberal en la que se emite un contrato social por la convivencia humana. Desde esa lógica, enumera algunos presupuestos que se deben considerar para desarrollar y potenciar el ejercicio ciudadano. Entre ellos, se relacionan las siguientes capacidades:

a. Desarrollo de la capacidad para hacer un examen autocrítico de sí y de las propias tradiciones. Cuestionar la vida no resulta un ejercicio simplemente útil, sino indispensable, que da sentido a la vida. Sin embargo, hay que estar atento a que esta indagación no sea solo del orden teórico, sino que tiene que estar vinculada con la experiencia propia y con otras experiencias para lograr un desarrollo en pos de un verdadero bien común.

b. Cada persona debe sentirse miembro o participante de una comunidad o una familia, más allá de las propias identificaciones regionales, étnicas, religiosas o de cualquier otra índole. En este sentido, Nussbaum parece atender las palabras de Diógenes el Cínico, cuando estipula que debemos ser ciudadanos del mundo. La idea de un ciudadano universal indaga no solo por el vínculo que debe existir entre un hombre o una mujer y su nacionalidad, sino aquel que existe también con la comunidad moral constituida por todos los seres humanos. Estos factores potencian el respeto por la dignidad humana, la razón y la libertad moral como derechos inherentes a todas las personas.

c. Tener la capacidad de situarse en el plano de los otros, de comprender su emocionalidad, sentimientos, aspiraciones, lógicas y demás aspectos que le dan valor y sentido a su existencia. Por tal motivo, la educación debe sumar incontables esfuerzos al pleno dominio de la lengua materna, de los simbolismos existentes en la cotidianidad y de la literatura que habla y trasmite la pasión con que se nutren las tradiciones. Ya decían los estoicos, como bien lo señala Nussbaum, que son mejores ciudadanos aquellos que han hecho un examen crítico de lo que en verdad importa, pues serán dueños de sus emociones y de sus pensamientos.

Entonces, formar ciudadanos libres desde la perspectiva de Nussbaum implica que aprendan a razonar por sí mismos y no a través de intermediarios o voceros; que argumenten correctamente; que diferencien los razonamientos de validez lógica; que distingan la estructura argumentativa y la intención de ciertos discursos; que por medio de premisas se acerquen a la verdad; que clarifiquen aquello en lo que creen; que pongan a prueba sus deducciones; que desenmascaren los prejuicios, y que la terquedad no ciegue sus convicciones.

Al respecto, Nussbaum (2014) advierte:

Pedimos a la educación superior que contribuya con una preparación general para formar ciudadanía, no sólo una preparación especializada para una carrera. Ha de extenderse los beneficios de esta educación a todos los 
ciudadanos, cualquiera que sea su clase, sexo, raza, origen étnico o religión. Esperamos que en un entendimiento mutuo y diverso, $\mathrm{y}$ en un examen profundo que cada uno haga de sí mismo, permitan acercar a los ciudadanos entre sí, y permitan formar una cultura democrática que sea deliberante reflexiva, en vez de ser simple colisión de preferencias carentes de análisis (p. 320).

En una mirada hacia un ideal de sociedades justas, estas no aspiran solamente a cuestiones de carácter económico; apuntan también hacia el desarrollo humano, en lo que tiene que ver con aspectos como la salud, la educación, los derechos, las libertades políticas y la calidad medioambiental, entre muchos otros, orientados todos a la búsqueda de unas mejores condiciones de vida, en una sociedad justa en la que hombres y mujeres sean vistos como iguales; en la que se recuperen y se construyan lazos de confianza, en un sentido de participación libre de intereses particulares, lleno de sentimientos colectivos. Nussbaum (2014) dice que el amor es importante para la justicia, y que ese amor debe trascender todos los escenarios de la sociedad. El amor de padres e hijos, de camaradas, e incluso el romántico, todos son capaces de inspirar una cultura pública de participación y de reconocimiento de la democracia.

\section{Marco metodológico}

\section{Perspectiva epistemológica}

Esta investigación se ubica dentro del paradigma cualitativo, donde se reconoce al sujeto y todo lo que le permite ser y actuar, que es la forma particular de relacionarse con los otros y con su entorno. Ello proporciona el insumo necesario para comprender la forma como los estudiantes -en este caso específico- expresan y configuran su acción en la construcción de realidades y sentidos de vida.

Siendo el objetivo de esta investigación lograr un acercamiento a los imaginarios de ciudadanía que tienen los estudiantes de primer semestre de Uniminuto Sede Principal e interpretar las posibles incidencias de la comunicación en la configuración de dichos imaginarios, se considera pertinente realizar el estudio desde el enfoque hermenéutico ya que permite alcanzar procesos interpretativos que propicien espacios de producción simbólica que ofrezcan apertura y reconocimiento acerca de las distintas realidades sociales, las cuales no se presentan como verdades absolutas sino como verdades desde la comprensión de la acción humana:

(...) mediante una metodología interpretativa se busca traspasar la barrera exterior sensible de acceder a su interioridad, esto es: a su significado; así queda descrita la esencial actitud frente a las cosas humanas que, condensada en el término griego hermeneuein alude a desentrañar o desvelar; dicha actitud ha dado lugar a una teoría y práctica de la interpretación conocida con el nombre de hermenéutica (Toledo, 1998, p. 205). 
De acuerdo con el propósito de esta investigación, el enfoque hermenéutico permite develar diferentes construcciones simbólicas que a través del uso de la descripcióngeneran un tipode conocimiento que reconoce la dinámica social como cambiante, por lo que posibilita múltiples miradas de acercamiento e interpretación de la realidad social.

\section{Tipo de estudio}

Este proyecto de investigación es un estudio de caso desarrollado en Uniminuto Sede Principal, que se orienta desde una perspectiva hermenéutica interpretativa, en un sentido totalmente cualitativo. Corresponde a un proceso exploratorio acerca de los imaginarios de ciudadanía de los estudiantes de primer semestre en esta institución de educación superior.

Todas las subjetividades que se tejen en el ámbito de la ciudadanía merecen un análisis riguroso y muy cuidadoso, ante todo porque se abordan las emocionalidades políticas y sociales de los estudiantes. Para esto, se considera muy asertivo el estudio de caso, pues según Hernández, Fernández \& Baptista (2003), «busca especificar propiedades, características, y rasgos importantes de cualquier fenómeno que se analice» (p. 119).

\section{Delimitación del caso de estudio y contexto}

Esta investigación se realiza con estudiantes de primer semestre de Uniminuto Sede Principal, cuyas edades oscilan entre los 16 y 25 años, quienes en buena medida cuentan con unas condiciones económicas, académicas y sociofamiliares no muy estables. Sin embargo, esto no se constituye en obstáculos para que el estudiante inscrito en Uniminuto logre unas transformaciones de fondo orientadas al mejoramiento de su calidad de vida. Por el contexto y modelo educativo de Uniminuto, desde el pilar de "la educación integral" se genera en el estudiante una mayor conciencia sobre las necesidades sociales actuales. El estudiante requiere reinterpretar nuevas maneras de reconocimiento de sus relaciones familiares y del uso de la comunicación como elemento mediador en los conflictos (Cárdenas, 2004). Es por eso que desde primer semestre y a través de asignaturas como Proyecto de Vida tienen la posibilidad de fortalecer, no solo las competencias académicas disciplinares, sino también sus habilidades sociales, desde una perspectiva reflexiva que los convierte en posibles agentes generadores de cambio.

\section{Técnicas e instrumentos de recolección de la información}

El taller pedagógico realizado en diferentes escenarios de trabajo fue la herramienta estructural para la recolección de la información y el desarrollo de los objetivos del estudio. En este caso, se aplicó en un espacio vivencial e interactivo: en las aulas de clase y en una plataforma virtual a través de una herramienta de trabajo colaborativo (wiki). Todo esto en el marco de la materia Proyecto de Vida, de Uniminuto Sede Principal. El taller pedagógico permitió un encuentro de saberes y de subjetividades a través de procesos comunicativos, vinculando narrativas que orientan el objetivo de esta investigación, en la que se estableció un diálogo con las percepciones, imaginarios y sentires de los participantes frente a la ciudadanía, para lo que el taller pedagógico cumple un papel importante al colocar a los investigadores de frente a los 
eventos comunicativos de los participantes. La herramienta permitió que afloraran las narrativas y los contenidos subjetivos por medio de procesos de libre expresión, debate, interacción, socialización, representación simbólica y construcción colectiva.

En su artículo) «Nuevos modelos de comunicación, perfiles y tendencias en las redes sociales», (Flores, 2009. p30) no dice que «la influencia de la cultura wiki hacia los medios de comunicación se basa en el desarrollo de la inteligencia colectiva y se fundamenta en el trabajo colaborativo» (p. 78). Con la finalidad de abordar de manera más integral la información, el taller pedagógico se aplicó en tres fases: la primera, en un espacio de acercamiento a la emocionalidad política de los participantes, a través del taller "Emociones Políticas"; la segunda, por medio de un encuentro de saberes, abierto y dialógico "Debate", y la tercera, mediante un ejercicio artístico de representación simbólica en una plataforma digital "Wiki Arte y Ciudadanía", todo ello con el objeto de visualizar los imaginarios que sobre ciudadanía tienen los estudiantes de primer semestre de Uniminuto Sede Principal, en la búsqueda de un encuentro con sus lógicas, sentires, estéticas, acciones, manifestaciones y emociones (ira, simpatía, asco, envidia, aflicción, culpa, miedo y amor, en todas sus expresiones).

El taller pedagógico se desarrolló con una muestra representativa de 120 estudiantes del curso Proyecto de Vida, de Uniminuto Sede Principal, un espacio de formación humana orientado al desarrollo integral en la sociedad. La población corresponde a estudiantes de cuatro cursos de la asignatura que pertenecen a carreras distintas, pues es un curso de formación transversal. En este espacio los estudiantes representaron diversas situaciones del accionar ciudadano, tanto individualmente como en grupos y en un trabajo colectivo; ellos expresaron su sentir emocional frente a las acciones propias y de otros, en el marco de la ciudadanía. Los estudiantes reflexionaron y debatieron sobre el tema en el aula de clase.

\section{Procedimiento metodológico}

Representación de esculturas humanas: como apertura del taller pedagógico primera fase- se realizó un ejercicio de representación de esculturas humanas en el que los estudiantes simbolizaron acciones y actitudes en el marco de la ciudadanía. En tal sentido, los estudiantes del curso Proyecto de Vida llevaron la escena pública a clase, construyendo figuras humas que representaban situaciones, acciones ejemplarizantes y de cuestionamiento del actuar propio y de otros en los diferentes escenarios sociales, e ideales ciudadanos de construcción colectiva. El ejercicio se realizó como estrategia de entrada a un clímax de confianza para incentivar la participación de los estudiantes en el taller. La dinámica rompe hielo se desarrolló en tres momentos. En el primero representaron individualmente esculturas humanas que hacían referencia a acciones ciudadanas con una connotación positiva y con un mensaje ejemplarizante; en el segundo, en grupos de cinco personas, simbolizaron situaciones vergonzantes y de connotación negativa del accionar propio y de otros; en el tercero, toda la clase representó una escultura humana como ideal del accionar desde la sinergia colectiva.

Taller de emociones políticas: los estudiantes de cada grupo recibieron 
un marcador y ocho trozos de papel de diferentes colores, prensados con un clip. Los docentes-investigadores contextualizaron a los estudiantes sobre ocho emociones políticas, sobre las cuales Nussbaum (2014) refiere que en cualquier espacio, en una democracia, están presentes siempre el miedo, simpatía, asco, envidia, culpa, aflicción y todas las formas de amor (p. 28). En este ejercicio de construcción de ciudadanía se solicitó a los participantes que relacionaran situaciones, acciones y sentires frente a las emociones propuestas por Nussbaum. De forma anónima, cada estudiante plasmó su sentir ciudadano frente a cada una de las emociones en una o varias palabras o frases cortas. Para ello se determinó un color de papel para cada emoción y se dio un espacio de 20 minutos para que las relacionaran. Posteriormente se les entregó cinta adhesiva para que pegaran sus trozos de papel en el tablero de clase, agrupándolas por zonas de color. Los estudiantes tuvieron la posibilidad de interactuar durante unos minutos mientras pegaban y observaban las expresiones escritas.

Debate: manteniendo la ambientación en el tablero en múltiples colores gracias a los trozos de papel con las expresiones, los participantes iniciaron de manera espontánea la segunda fase del taller pedagógico a través de un debate sobre los temas y experiencias en el ejercicio anterior y su relación con la realidad social, actividad que duró aproximadamente 20 minutos en cada uno de los cursos trabajados. Los docentes-investigadores mantuvieron su papel de moderadores en lo que concierne al orden y la organización, $\mathrm{y}$ fungieron como articuladores de los ejes temáticos desarrollados. En el espacio hubo libertad de expresión y confrontación, y se trabajó desde la participación en un sentido democrático. Como cierre magistral del taller se retomó la última fase propuesta en la dinámica rompe hielo, en la que los jóvenes estudiantes representaron una acción desde un sentir colectivo sobre una ciudadanía ideal, a fin de abrir un espacio de reflexión al respecto. El taller se registró audiovisual y fotográficamente, para su posterior transcripción en el proceso de sistematización de la información.

Wiki Arte y ciudadanía: en la última fase del taller pedagógico se trabajó sobre la "Wiki Arte y ciudadanía", entendido como un espacio de construcción de ciudadanía desde el arte. El objetivo fue conocer de cerca el sentir social y las diversas posibilidades en los imaginarios de ciudadanía de los jóvenes estudiantes a través de representaciones en el arte en todas sus expresiones. El objeto de la actividad fue indagar sobre sus subjetividades en el sentir ciudadano sin recurrir a un modelo liberal en este sentido, y, más bien, desde una perspectiva amplia y sin limitaciones.

En este espacio de participación desde el arte se realizó una exposición que relaciona una reflexión profunda, en una extensión de resignificación desde la experiencia previa de una visita al Museo de Arte Contemporáneo, como estrategia de sensibilización frente al accionar ciudadano. Los estudiantes encontraron en esta experiencia la posibilidad de apreciar las exposiciones de tres artistas: de Maquiamelo: "Divas", expresión en cabezas reducidas, en un sentido de reflexión acerca del consumismo y la estética; de la mexicana Alejandra Baltazares: "Muñecos de Loza", obras en relación a género y memoria, y de Falon Cañón: "Ruido Negro", obras que abordan 
el tema: de los desechos a la transformación del medioambiente. La visita al museo (guiada, que duró una hora y contó con la participación de todos los involucrados en el muestreo representativo) sirvió como antesala para una invitación a representar diversas situaciones sociales relacionadas con la ciudadanía, a través de pequeñas muestras artísticas.

Después de esta experiencia de encuentro con el arte, se solicitó a los estudiantes partícipes del muestreo que realizaran una obra de arte con un contenido social que expresara un sentir ciudadano. Luego se los invitó a que realizaran una exposición virtual por medio de un wiki en el aula virtual del curso Proyecto de Vida, exposición que fue apreciada por todos los participantes. Toda la información se guardó por medio de capturas de pantalla para su sistematización y análisis.

Como parte del diseño metodológico se habilitó un espacio digital en el aula virtual del curso Proyecto de Vida. Dicho espacio se articuló a manera de wiki con el fin de que los estudiantes pudieran participar activamente en un trabajo colaborativo en el que necesariamente se tuviesen que generar procesos de interacción y convivencia. El escenario digital se articuló con tres salas de exposición que se ambientaron con imágenes alusivas al arte. Técnicamente se establecieron mecanismos para que los estudiantes pudieran subir imágenes de obras de arte de su propia autoría, las cuales debían tener una relación con el sentir ciudadano en múltiples posibilidades. También se dotó el espacio virtual con herramientas para la digitación de los textos descriptivos y para el tránsito por las salas de exposición.

\section{Análisis de la información}

En el libro Técnicas Cualitativas de Investigación Social (tercera parte: «Elementos de Análisis Cualitativo») Valles (2007) ofrece elementos estructurales para el proceso de análisis de la información. Según Valles, «Se entiende por análisis la utilización de una serie de procedimientos y técnicas, una vez obtenidos los datos» (p. 340). La amplitud y la no estandarización propia de la investigación cualitativa permitieron un acercamiento a las subjetividades en los eventos comunicativos de los estudiantes participantes en el taller pedagógico aplicado en cada una de las tres fases ya mencionadas.

El procedimiento analítico The Discovery of Grounded Theory (Glaser y Strauss, citados por Valles, 2007, p. 346), sobre cómo analizar datos en el estudio de caso, sirvió como base para el proceso de análisis de la información. El caso de Uniminuto Sede Principal involucró seleccionar una muestra representativa de estudiantes para obtener la información, la que se procesó mediante la propuesta estructural de los siguientes mecanismos: a) análisis de contenido clásico (denominado hoy análisis de contenido cuantitativo) de los datos brutos para la categorización inicial; b) desarrollo de las categorías iníciales, c) integración de categorías y sus propiedades; d) delimitación de la teoría, y e) escritura de la teoría. Desde la perspectiva de The Discovery of Grounded Theory, estos cinco aspectos son fundamentales para el proceso de análisis de caso.

Uno de los sustentos teóricos que orientan el análisis del discurso es el propuesto por Van Dijk (1999). Su modelo apunta a identificar 
las tendencias y subtendencias en el uso de los lenguajes de los participantes. Es un elemento fundamental para el proceso de análisis ya que en las tres fases del taller pedagógico emergieron contenidos que ameritan una mirada especial desde los lenguajes y las prácticas discursivas de los estudiantes. El aporte de Van Dijk orientó además en la determinación de las tendencias hacia las categorías emergentes.

Los datos obtenidos a través del taller pedagógico en cada una de sus aplicaciones proporcionaron una gran cantidad de información cualitativa que alimentó un amplio número de categorías. En este sentido y para lograr una delimitación más precisa sobre los temas que más relacionaron los participantes, se recurrió al llamado "Análisis de contenido clásico" (hoy análisis de contenido cuantitativo). Considerando que aunque esta propuesta investigativa es absolutamente cualitativa, sí era necesario dar un paso por lo cuantitativo. Esto permitió un acercamiento a las categorías emergentes más significativas desde la estadística, las cuales resultaron merecedoras de especial atención y contribuyeron a la toma de decisiones por parte del equipo investigador en relación con su pertinencia. En este caso, se hizo una conversión de los datos cualitativos a cuantitativos a través de procesos estadísticos. Se inició con la codificación de la información y la sistematización de los contenidos de cada una de las emociones políticas de los participantes para llevarlos a un sistema cuantificable en las matrices de análisis. Dicha codificación se dio a través de las tabulaciones y de la asignación de color a cada una de las tendencias temáticas, de la misma manera que en el debate realizado en clase y en la Wiki Arte y Ciudadanía, tras asignar un número a cada una de las obras de arte.

Este mecanismo permitió un trabajo comparativo con los datos en bruto obtenidos por medio de las tres fases del taller pedagógico. Es el caso de su aplicación para las emociones políticas, las opiniones generadas en el debate de ciudadanía (recogidas en vídeo y transcritas a texto) y la información obtenida de la descripción y la relación semiótica de las obras de arte realizadas y expuestas en la Wiki Arte y Ciudadanía. Otro elemento importante en este proceso de análisis de la información y que se fundamenta desde el mismo referente teórico fue el desarrollo de las categorías iníciales. En este caso, las expresiones en cada una de las fases del taller pedagógico apuntaban hacia diferentes escenarios sociales y a múltiples situaciones y contextos. Toda la información obtenida configuraba un gran número de categorías, para lo que fue necesario hacer una codificación abierta, desde la trascendencia, amplitud, profundidad y dimensionalidad. En este sentido, Valles (2007) cita a Strauss y Corbin: «El proceso en marcha, de codificación abierta estimula el descubrimiento no sólo de categorías sino también de sus propiedades y dimensiones» (p. 350). Esta propuesta permitió una orientación hacia la configuración de categorías más amplias, logrando la visualización de veintitrés de ellas, teniendo en cuenta que la información inicial alimentaba más de cuarenta ejes temáticos. En la Tabla 1 se relacionan los ejes temáticos más relevantes y que permitieron configurar las categorías iniciales. 
Tabla 1. Configuración de categorías iniciales.

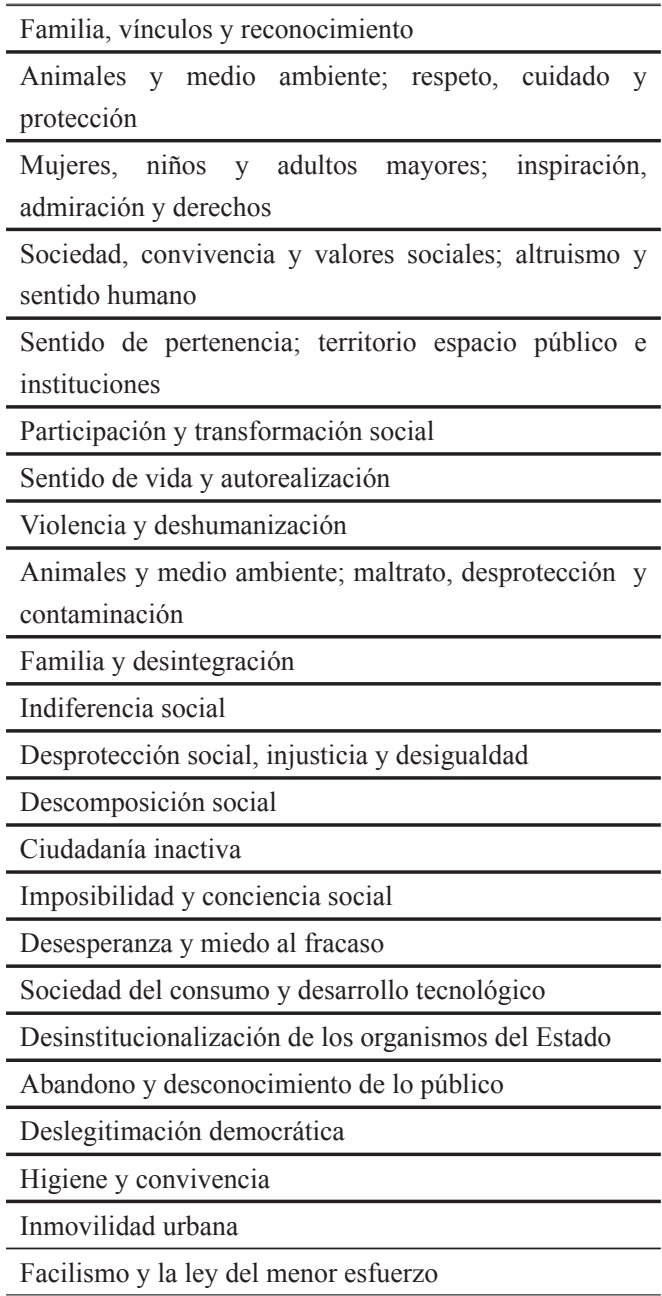

\section{Fuente: Elaboración propia}

La información obtenida mediante la implementación del taller pedagógico en sus tres fases se sistematizó a través de la trascripción y digitalización de los contenidos que se consolidaron con las expresiones de los participantes. En el caso del taller de emociones políticas, cuyo fundamento teórico se da en la propuesta de Nussbaum (2014) — para quien «Todas las sociedades están llenas de emociones» (p. 13)-, recibió expresiones con un alto contenido emocional. Las palabras y frases se transcribieron y ubicaron en la matriz de análisis de acuerdo con el color determinado para su referenciación. Durante la aplicación del instrumento se informó a los participantes sobre el color correspondiente a cada emoción; por la tanto, sus expresiones ya tenían un direccionamiento a cada una de ellas. Es así como al recoger los contenidos del taller en la primera fase, las emociones políticas (amor, ira, miedo, envidia, aflicción, simpatía, culpa y asco) se alimentaron en la matriz de análisis con cada una de las expresiones de los participantes.

Los contenidos registrados en formato audiovisual sobre la aplicación de la segunda fase del taller pedagógico - en la que se desarrolló un debate abierto sobre los sentires de los participantes en torno a la ciudadanía - fueron transcritos y vinculados a la matriz de análisis. En esta ocasión, el equipo investigador hizo uso de la interpretación y del análisis crítico del discurso con el fin de hallar tendencias hacia alguna emoción política en particular. Según Van Dijk (1999):

El análisis crítico del discurso es un tipo de investigación analítica sobre el discurso que estudia primariamente el modo en que el abuso del poder social, el dominio y la desigualdad son practicados, reproducidos, $\mathrm{y}$ ocasionalmente combatidos, por los textos y el habla en el contexto social y político (p. 24).

El ejercicio de digitalización de la información directamente en la matriz de 
análisis, realizado para la primera fase del taller pedagógico, sirvió de base para integrar la información de la segunda fase, correspondiente al debate. En la primera fase, la información ya venía orientada directamente por los participantes, pero en la segunda el equipo de investigación decodificó los contenidos, aunque muchos de ellos ya habían sido expresados con claridad en la interlocución del debate.

Hasta este punto del análisis de la información, los contenidos estaban referenciados directamente con las emociones políticas, ya incluso con un color asignado por emoción. Pero en la sistematización de la tercera y última fase del taller pedagógico, en la que los participantes crearon obras de arte e hicieron una titulación y descripción, fue necesario hacer una interpretación de los contenidos textuales y semióticos para articularlos a la matriz de análisis. Las obras de arte presentadas en la Wiki Arte y Ciudadanía (espacio de interacción de los estudiantes en la plataforma virtual del curso Proyecto de Vida de Uniminuto Sede Principal) estaban relacionadas con el sentir ciudadano en todas sus manifestaciones. Toda la información se procesó de tal manera que cada expresión se integrara a una emoción en particular. A diferencia de la articulación de las dos primeras fases del taller pedagógico a la matriz de análisis, esta última contó con la vinculación de las capturas de pantalla como soporte del proceso.

Ya consolidada la información en la matriz de análisis determinada para cada fase del taller pedagógico, pero con una base en común que permitiera la posterior articulación en una sola estructura, se procedió a relacionar cada contenido ya ubicado en la matriz con una categoría inicial. En un primer momento se visibilizaron más de cuarenta ejes temáticos que se orientaban desde palabras claves, a las que les fue asignando un color en particular que permitiera un camino hacia una categoría emergente. Algunos contenidos se presentaron en un sentido de denuncia, y otros de aprobación, rechazo, exaltación, etc., en fin, una información demasiado amplia pero que daba pistas de fusión en contenidos más integrales, para lo que fue necesario utilizar un bloc de papel para escribir, relacionar y transversalizar la información. De este proceso se logró el resultado de 23 categorías iniciales, las cuales se orientaban en diferentes connotaciones. Dichas categorías se renombraron y referenciaron a través de nuevos colores. Todo el proceso se llevó a cabo en la matriz de análisis compuesta por las tres fases del taller pedagógico.

Después de un trabajo riguroso de relación y categorización inicial, fue necesario hacer uso de un proceso de análisis cuantitativo que permitió determinar la recurrencia de las participaciones en relación con las emociones políticas y las categorías emergentes. La estadística, en este caso, permitió la visualización de unas categorías mucho más representativas, que acaparaban en mayor número las expresiones con el sentir ciudadano de los estudiantes participantes.

El consolidado final abre las puertas a ocho categorías emergentes finales, cuya representatividad se focaliza en este trabajo de investigación y será presentada en detalle más adelante en el informe de resultados. 


\section{Resultados}

En este capítulo se exponen los resultados del proyecto de investigación, que más que un mecanismo para optar por un título en Maestría en Comunicación Educativa, es un aporte a la construcción ciudadana. Al mismo tiempo, el trabajo contribuye a los procesos de investigación social de la Universidad Tecnológica de Pereira, de la cual hace parte la maestría que hoy acompaña esta experiencia.

La orientación hacia los jóvenes estudiantes en Proyecto de Vida, espacio de resignificación de sentido humano y social, demanda de los docentes un acercamiento a sus sentires sociales y a sus emociones políticas, como bien lo titula Nussbaum (2014) en su libro Emociones Políticas ¿Por qué el amor es importante para la justicia? Esta es una de las grandes razones, que sumada al deseo de aportar a la construcción social, permite embarcarse en un viaje hacia el acercamiento a los imaginarios de ciudadanía de los estudiantes de primer semestre de Uniminuto Sede Principal.

Para lograr un acercamiento a los sentires de los estudiantes frente a la ciudadanía, se decide, en principio, no poner de manifiesto ningún modelo que permitiera rutas hacia el reconocimiento de prácticas de ciudadanía liberal; más bien, se esbozó un mecanismo que diera espacio a un encuentro con las subjetividades sociales a través de la emocionalidad política. Es Martha Nussbaum quien con su teoría da luces hacia la concepción de la ciudadanía desde la emocionalidad, y quien abre las puertas a este escenario de diálogo con los nuevos imaginarios de ciudadanía.

\section{Emocionalidad política}

En este espacio se trabajó el sentir de los estudiantes a través de las siguientes emociones: amor, simpatía, aflicción, culpa, miedo, envidia, ira y asco, con el fin de que reconocieran sus propias acciones y las de otros en relación con la ciudadanía. Ante la gran pregunta: ¿Qué de sus propias acciones y las de otros, en relación con la ciudadanía, les genera amor, simpatía...? Los estudiantes expresaron todo su sentir a través de frases en las que reconocieron, aprobaron, denunciaron, repudiaron, aplaudieron, destacaron, sancionaron $\mathrm{o}$ rechazaron con vehemencia las prácticas ciudadanas propias y de otros.

- Amor: sobre el amor, en todas sus expresiones y relaciones, los participantes en el taller pedagógico resaltaron el amor a la familia, a la pareja y la conservación del vínculo afectivo, el amor por el otro y lo otro, por los animales y por sí mismos. Destacaron especialmente el altruismo, los testimonios ejemplarizantes sobre actos de sencillez, el respeto, la humildad en el reconocimiento de los errores, el don de servicio, la comprensión. De otro lado, aplauden y certifican la tolerancia, el respeto por la diferencia y el sentido de pertenencia. Hablan del amor a la patria, a la ciudad, a la tierra, al arte, a la cultura, al deporte, a la profesión, a la literatura y a la sociedad en general. También dejaron ver expresiones en las que relacionan la unidad, el compartir y las causas nobles, especialmente aquellas que integran trabajo y proyectos para los niños. Los jóvenes estudiantes expresaron sentir amor por las expresiones de afecto, por la sonrisa amable y por la gente que irradia felicidad 
- Simpatía: los sentires que más destacaron los estudiantes participantes en relación con la simpatía se orientan a la buena utilización de los recursos, a la ayuda a los ciudadanos, al cuidado del medioambiente y al sentido de pertenencia. También hacia valores sociales como la unión, la solidaridad, la generosidad, la amabilidad, la bondad, la honestidad, la comprensión y la humildad. En sus expresiones se relacionaron además escenarios sociales como el deporte, el arte urbano, los eventos culturales y los espacios de recreación. Aparecieron además el reconocimiento y respeto por los niños y los adultos mayores. Asimismo, les generaron simpatía acciones como el compartir con la familia y amigos, el buen humor, la sonrisa amable, el abrazo fraterno, la alegría y el disfrute de cada momento. Expresaron sentir conexión con espacios, lugares y territorios, además con el emprendimiento, las transformaciones sociales y las campañas que fomentan la construcción social.

- Aflicción: de acuerdo con los resultados obtenidos en la aplicación del taller "Emociones Políticas", los participantes manifestaron que ver personas en la calle desprotegidas y la impotencia de no poder ayudarlas les aflige demasiado, así como ver a otros seres vivos en situación de desprotección. Les preocupa la indiferencia, la violencia en todas sus expresiones, la discriminación, el maltrato a los niños, mujeres y adultos mayores. Es recurrente en sus manifestaciones la palabra deshumanización, la que entienden como la pérdida de respeto por la vida y por la dignidad humana. Con ella relacionan los asesinatos de líderes políticos, la vulneración de los derechos humanos, la descomposición social, la degradación del ser, el abandono, la utilización de los niños y el abuso sexual. Les conmociona el sufrimiento de las personas y animales, la contaminación y la injusticia social. Denuncian a través de sus expresiones la corrupción, la falta de educación y de oportunidades laborales y profesionales. De manera especial les inquieta su futuro en lo que tiene que ver con el cumplimiento de sus metas, propósitos y desarrollo social y profesional.

- Culpa: no ayudar si se tiene la oportunidad, callar, no denunciar, ser indiferentes ante situaciones de violencia y maltrato, la humillación a otros, la intolerancia, contaminar el medioambiente, no dar pasos de liderazgo y representación, no participar y no luchar por sus ideales. Estas situaciones las relacionas desde la acción, pero también desde la omisión. También se manifiestan frente a prácticas cotidianas en los sistemas de transporte público y espacios comunes, entre las que se destacan el "no ceder la silla en Transmilenio" y "no dejar la basura en lugares apropiados". Algunos estudiantes confiesan hacerse los dormidos para evitar entregar el puesto en los sistemas de transporte público. Por otro lado, hablaron del consumismo y del desperdicio de los alimentos, de no respetar las normas de tránsito y de no escuchar ni dar espacios a las opiniones de otros. En un sentido de reflexión profundo en su dimensión espiritual, expresaron sentires en relación con el poco valor por la vida y por lo que se tiene, de que los demás paguen por sus errores, de ser infieles, de mentir, de no aportar a la familia y de vulnerar a los seres que aman.

- Miedo: el miedo a denunciar por temor a represalias, a los actos delictivos en las calles, a la violencia, 
a la deshumanización, a la injusticia, a las reacciones desmedidas y a la muerte, hacen parte de los sentires de los jóvenes estudiantes. Sobre la muerte, se teme desde la pérdida por acciones de violencia, irresponsabilidad, hasta por el desprendimiento de la vida. Del mismo modo, aparecen temores relacionados con la soledad, el juicio, el fracaso, la conquista de la felicidad y la pérdida de la fe y la esperanza. En algunos casos se encontraron expresiones que vinculan el futuro con las oportunidades y con el mundo profesional y laboral, con la inequidad, la destrucción del planeta y el avance tecnológico desmedido.

- Envidia: los jóvenes estudiantes expresaron al respecto que las cosas no merecidas y sin esfuerzo, las oportunidades de desarrollo profesional y social para algunos, el elitismo, las mejores condiciones de calidad de vida, el progreso y las posiciones económicas representan para ellos situaciones que deberían enmarcarse dentro de los principios de equidad y de respeto por los derechos. Una envidia no tan justificada aparece para relacionar la felicidad de otros, el triunfo y los logros, sin importar si son merecedores o no de ellos. También se relacionan mayores capacidades intelectuales, la construcción de sentido de vida, la alegría, el emprendimiento, la riqueza cultural y la ciudadanía activa en otros territorios distintos al propio.

- Asco: la morbosidad, la perversión, el abuso sexual, la maldad, la crueldad, la barbarie, el maltrato a las personas y animales y todas las formas de violencia generan emociones de repudio. En un diálogo entre emociones, la culpa, en muchos casos, vincula una reflexión sobre acciones propias que también generan asco.
Ira: en relación con esta emoción, los estudiantes expresaron que el ego, el clasismo, la prepotencia, la ironía, el sarcasmo, la inconsciencia, la mentira y la falta de respeto y valores logran encauzar su nivel de reacción hacia la ira. Estas situaciones de atropello se denuncian en las expresiones logradas en este espacio, que no solo vinculan a otros, sino a sí mismos. La indigencia, la pobreza, la desigualdad y la miseria son situaciones que ponen de manifiesto la inconformidad de los ciudadanos pues son enmarcadas en espacios de desprotección. Aunque estas denuncias se vinculan con acciones, los jóvenes estudiantes también la relacionan con omisiones, como la indiferencia, la desconexión y la apatía, en un sentido reflexivo sobre lo que pasa a su alrededor y lo que nace de sí mismos.

\section{Discusión de los resultados}

Después de un trabajo riguroso de revisión y relación de los datos que arrojó el taller pedagógico en sus tres fases (emociones políticas, debate y Wiki Arte y Ciudadanía) y tras abordar cada una de las veintitrés categorías iníciales, luego de una mezcla de emociones, se logró un diálogo profundo con las subjetividades sociales de los jóvenes universitarios a través de la muestra representativa de los estudiantes de primer semestre de Uniminuto Sede Principal. Teniendo en cuenta el número de participaciones de los estudiantes en relación con su sentir ciudadano y después de pasar por diferentes situaciones en las que se entretejen las subjetividades emocionales de los participantes, se logró un encuentro con los sentires que sobre la ciudadanía tienen los estudiantes de primer semestre de Uniminuto Sede Principal. Sus percepciones y visiones sobre lo que 
pasa en sus contextos sociales y sobre sus ideales se manifiestan a través de las siguientes categorías emergentes (Tabla 2).

Tabla 2. Categorías emergentes, análisis cuantitativo.

\begin{tabular}{|c|c|c|c|}
\hline 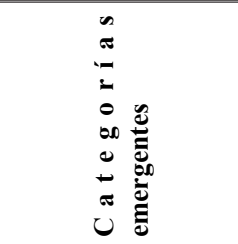 & 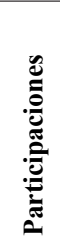 & $0^{\circ}$ & \\
\hline $\begin{array}{l}\text { Violencia } \begin{array}{l}\text { deshumanización }\end{array}\end{array}$ & 130 & 21,04 & \multirow[b]{2}{*}{$\begin{array}{l}\text { Participaciones más } \\
\text { representativas con } \\
\text { recurrencia en las } \\
\text { matrices de análisis } \\
1 \text { y } 3\end{array}$} \\
\hline $\begin{array}{l}\mathrm{S} \text { o c i e d a d, } \\
\text { convivencia } \\
\text { valores sociales. } \\
\text { Altruismo y sentido } \\
\text { humano }\end{array}$ & 110 & 17,80 & \\
\hline $\begin{array}{l}\text { Desprotección } \\
\text { social, injusticia y } \\
\text { desigualdad }\end{array}$ & 144 & 23,30 & \multirow{4}{*}{$\begin{array}{l}\text { Participaciones más } \\
\text { representativas en } \\
\text { la matriz de análisis } \\
1\end{array}$} \\
\hline Indiferencia social & 98 & 15,86 & \\
\hline $\begin{array}{l}\text { Familia, vínculos y } \\
\text { reconocimiento }\end{array}$ & 50 & 8,09 & \\
\hline $\begin{array}{l}\text { Animales y medio } \\
\text { ambiente; maltrato, } \\
\text { desprotección y } \\
\text { contaminación }\end{array}$ & 51 & 8,25 & \\
\hline $\begin{array}{llll}\text { Sociedad } & & & \text { del } \\
\text { consumo } & & & \text { y } \\
\text { d e s a r r o l } & 1 & 1 & 0 \\
\text { tecnológico } & & & \end{array}$ & 23 & 3,72 & \multirow{2}{*}{$\begin{array}{l}\text { Participaciones más } \\
\text { representativas en } \\
\text { la matriz de análisis } \\
2\end{array}$} \\
\hline $\begin{array}{l}\text { Sentido de vida y } \\
\text { autorrealización }\end{array}$ & 12 & 1,94 & \\
\hline TOTAL & 618 & 100 & \\
\hline
\end{tabular}

Fuente: Elaboración propia

Violencia $y$ deshumanización: el contexto de violencia en Colombia y la desmitificación de la vida, que se refleja a diario con actos atroces en los que cada vez se trazan marcas récords de deshumanización, muestran una radiografía social que despierta los sentires de los jóvenes. Emociones como la aflicción, el miedo, la ira, el asco y hasta la culpa logran estremecer y despertar su sensibilidad. Siempre hay conmoción, pero no siempre acción, pues la indiferencia hace de las suyas y en muchos casos se dejan pasar acciones repugnantes. Los estudiantes participantes orientaron sus sentires hacia esta categoría; sus expresiones muestran aflicción por la pérdida de respeto por la vida y por el aumento desmedido de la violencia, no solo en sus entornos cercanos, sino también en el mundo. La violencia física y sexual, las masacres, el abandono de niños y animales, los actos de barbarie, el accionar de los grupos al margen de la ley, entre muchos otros comportamientos desgarran el corazón de muchos jóvenes, pero para otros pasan también inadvertidos. Lo cierto es que estas acciones están muy presentes en sus imaginarios. De otro modo, la culpa aparece para abrir un espacio reflexivo sobre la indiferencia que muchos de los participantes aseguran haber tenido.

Esta categoría de violencia y deshumanización tuvo el porcentaje de relación más alto en todo el proceso. De 618 participaciones en las tres fases del taller pedagógico, que corresponden solamente a las 8 más representativas en términos cuantitativos, 130 se vinculan con esta categoría $(21,04 \%)$. Este resultado deja ver unos imaginarios frente a la ciudadanía en los que se establece una denuncia en relación con la justicia, la seguridad, el conflicto y la degradación del ser humano.

\section{Sociedad, convivencia y valores sociales -} altruismo y sentido humano: el accionar cotidiano en una megaciudad como Bogotá, en la que se desarrolla la cotidianidad de los estudiantes de Uniminuto Sede Principal y, por supuesto, de los que se encuentran en primer semestre, se 
destaca hoy en una categoría emergente que vincula la sociedad, la convivencia $\mathrm{y}$, especialmente, los valores sociales. De estos últimos los participantes dan cuenta a través de emociones como la simpatía y el amor. Asimismo, por un lado denuncian la desconexión y la falta de sinergia colectiva, pero por el otro reflexionan y reconocen el altruismo de muchos. Para los jóvenes estudiantes, los actos desinteresados, la humildad y el ponerse en los zapatos del otro son acciones que generan admiración y reconocimiento, aunque en muchas de sus expresiones se siente un panorama desesperanzador. En esta categoría, que se ubica en segundo lugar con 110 participaciones $(17,8 \%)$, se destacan el valor por el liderazgo, el sentido social y los mecanismos de convivencia.

\section{Desprotección social, injusticia y} desigualdad: esta categoría logra una visibilización a través de emociones como la envidia, la ira, el miedo y la aflicción. La envidia, que para muchos tiene una connotación negativa, en este caso puede ser un mecanismo de expresión para hacer denuncias en relación con los principios de igualdad. Un gran número de estudiantes participantes se expresaron en este sentido, relacionando situaciones en las que no se tienen las mismas oportunidades que otros o en las que se evidencia el facilismo de muchos para obtener beneficios sin mayor esfuerzo. El miedo, la aflicción y la ira son emociones que en este caso representan el sentir de los participantes en relación con la injusticia y la desprotección social. Estas situaciones les afligen y les generan incertidumbre, pero también despiertan en ellos emociones más fuertes y contundentes como la ira. Es términos de recurrencia $\mathrm{y}$ de acuerdo con las intervenciones en el taller pedagógico, esta categoría emergente se ubica en segundo lugar con 144 participaciones $(23,30 \%)$. En esta categoría se expresa el sentir ciudadano frente al respeto por los derechos de los seres humanos.

Indiferencia social: con 98 participaciones $(15.86 \%)$, la indiferencia social aparece en el imaginario de los jóvenes estudiantes de primer semestre de Uniminuto Sede Principal. Ellos reconocieron que en muchos casos son indiferentes frente a lo que pasa en sus entornos sociales y que la indiferencia es recurrente en la cotidianidad de los colombianos. La desconexión y el desapego del otro no permiten un sentir colectivo, y el individualismo y el egoísmo son emociones que emparentan con la envidia.

Familia, vínculos y reconocimiento: el amor y la simpatía juegan un papel importante en los imaginarios de ciudadanía que vinculan el reconocimiento de la familia como base de la sociedad. Un gran número de participantes expresaron sentir amor por sus familias, por sus parejas y por sus amigos; destacan la unión familiar y reflexionan sobre su papel en los vínculos familiares. La culpa les ha permitido en algunos casos una resignificación de las relaciones comunicativas al interior de sus familias. La admiración y el respeto por quienes valoran el sentido de familia también se manifiestan en sus expresiones, dejando ver unos sentimientos positivos en esta categoría emergente. Con 50 participaciones $(8,09 \%)$, de acuerdo con la matriz de análisis cuantitativo, la categoría se ubica como la sexta en recurrencia.

Animales y medio ambiente; maltrato, desprotección y contaminación: así como en una de las categorías iníciales, en la que 
se destacó el amor y respeto por los otros seres que no son humanos, en esta y con mayor recurrencia en las participaciones se denuncia el maltrato y la desprotección de los animales y el medioambiente. Sentimientos como el asco, la ira, la aflicción y la culpa generaron reflexiones profundas en los participantes. Los hechos en los que se ejerce violencia hacia los animales se repudian y ponen en muchos casos en el escarnio público. La repulsión estomacal y el rechazo contundente hacia los actos de maltrato estremecen de rabia y dolor a los jóvenes, quienes en muchos casos reconocen la culpa de haber hecho parte de la inconsciencia de la que hoy hablan. La contaminación ambiental les aflige y les causa ira y miedo, pero no siempre dan pasos hacia la concientización, aunque muchos sí lo hacen a través de campañas en las redes sociales. Con 51 participaciones $(8,25 \%)$, esta categoría emergente se ubica en un quinto lugar.

\section{Sociedad del consumo y desarrollo} tecnológico: esta categoría en particular se alimentó de los sentires de los estudiantes en la ejecución del taller "Wiki Arte y Ciudadanía", espacio en el que tuvieron la oportunidad de exponer sus obras de arte en relación con la ciudadanía. Sus expresiones artísticas vincularon denuncias sobre el consumismo y la dependencia de los artefactos electrónicos y digitales, sobre la utilización de la mujer como mercancía en términos publicitarios, sobre la manipulación de los medios de comunicación y la dependencia de la belleza estética. Cuestionaron actitudes $\mathrm{y}$ situaciones en las que se antepone el estereotipo de belleza física como único medio para sobresalir en la sociedad. Para algunos estudiantes, estas acciones generan sentimientos como la ira, la aflicción y la culpa, pues en relación con esta última, reconocen hacer parte de las dinámicas de los mercados y alimentar el consumismo. 23 participaciones en este sentido $(3,72 \%)$ dan cuenta del sentir de los estudiantes en relación con esta categoría emergente.

\section{Sentido de vida y autorrealización:} el amor y la simpatía permitieron la configuración de esta última categoría emergente, que con 12 participaciones $(1,94 \%)$ expresa el sentir de los jóvenes en relación con su dimensión afectiva El amor propio y el respeto por la vida son el común denominador en este espacio; aquí está su sentido de proyección social, la superación, la resiliencia y, en especial, su proyecto de vida. En sus imaginarios de ciudadanía aparece la trascendencia como un factor de desarrollo social y el espíritu de superación personal puede ser el motor para la transformación de sus entornos hacia una mejor calidad de vida. En sus expresiones dejaron ver además la admiración y respeto por aquellos que se convierten en testimonio de vida para otros. También lograron reflexiones acerca del valor y el sentido de vida.

\section{Imaginarios de ciudadanía}

A continuación, se presentan los ocho imaginarios de ciudadanía más relevantes. Producto de la interpretación profunda de las categorías emergentes, en el proceso se utilizó la antonimia para el caso del reconocimiento de elementos negativos en algunas categorías.

Respeto: en un sentido de reconocimiento del valor del otro y lo otro, el respeto aparece en el imaginario de los estudiantes participantes. Sus sentires se orientan hacia la denuncia de la violencia y 
deshumanización que se ejercen contra las personas y los otros seres. Claman por la integridad y el respeto de los seres humanos en general, y de los animales y el medioambiente. Conciben el respeto como un elemento fundamental en el accionar ciudadano y en la construcción social, muy distante de las prácticas de abuso, maltrato, discriminación y de todas las formas de violencia que no necesariamente está enmarcadas en acciones contundentes de agresión física, sino que trascienden a lo psicológico y a la vulneración de los derechos humanos.

Justicia: se entiende desde los valores sociales en relación con los principios de respeto, igualdad, equidad y verdad. Así aparece en el imaginario de los jóvenes estudiantes pues sus posturas dejan ver un profundo sentir de rechazo hacia la desigualdad, la corrupción, la iniquidad, y hacia el atropello, la desprotección y el abandono del Estado y de los entes gubernamentales. Sugieren el estado de indefensión y la injusticia como barreras para la construcción de ciudadanía, y dejan ver en sus sentires que la justicia es determinante en la motivación del ejercicio ciudadano.

Empatía: encarnar la realidad ajena y ponerse en los zapatos del otro es para el imaginario de los estudiantes un mecanismo ciudadano que va en contra de la indiferencia, la apatía y la desconexión que tanto inciden en su emocionalidad. La ira y la aflicción son sentimientos que denuncian la falta de conciencia social que tanto daño le hace a la sociedad. Ser empático es abrir las puertas a la conexión con el otro, a sus necesidades y a sus sentires; por lo tanto, constituye un elemento de construcción ciudadana.
Altruismo: desde el sentir y la acción desinteresada en beneficio del otro hasta el trabajo en comunidad. Así aparece el altruismo como un imaginario de ciudadanía que reposa en el pensamiento de los participantes y que puede constituirse en uno de los pilares de la ciudadanía en la sociedad actual. Las acciones que se orientan en este sentido reciben sus aplausos, que no expresan con sus manos, sino que los sienten en su interior a través de la simpatía y el amor.

Idealismo: se entiende desde la armonía social, sin excesos ni materialismo, y no visto como un ideal inalcanzable. En sus expresiones en el taller pedagógico, los participantes manifestaron preocupación por aquellos que configuran su vida entorno a las cosas materiales, que son dependientes del mercado y que dan valor a las personar con base en lo que económicamente poseen. Según ellos, esto atenta contra el buen ejercicio de la ciudadanía, y sus sentires se mueven en emociones como la ira, el asco y la aflicción. De otro lado, el desmedido avance tecnológico es para ellos un tema de preocupación, pues consideran que la mala apropiación de dispositivos y artefactos puede conducir a la desintegración social. Es el idealismo entonces otro de los elementos fundamentales para la ciudadanía pues permite un aporte importante a la armonía social.

Sinergia colectiva: en sus expresiones, el sentir colectivo se muestra para los participantes como uno de sus imaginarios de ciudadanía. Según ellos, el individualismo y la falta de conexión atentan constantemente contra el ejercicio ciudadano y es una de las grandes razones que no permiten el buen desarrollo de las sociedades. Dejan ver que con la unidad 
y la sinergia colectiva se puede crecer en grupo, se puede sentir al otro y se puede trascender socialmente. También sugieren que la vulneración de los derechos, la corrupción y gran cantidad de situaciones distantes a la construcción social obedecen al individualismo. Es pues para ellos la sinergia colectiva una forma de acercamiento a la resignificación de la ciudadanía.

Sentido de familia: el amor, la unión y la familia como base social se relacionan en este imaginario. Para los estudiantes, la desintegración, la falta de afecto, de apoyo, las malas relaciones y la no apropiación de los valores sociales afectan de manera negativa la ciudadanía. Sin cuestionar los modelos de familia y sin debatir los roles al interior de la familia, aparece en ellos el deseo de exaltar la importancia de tener sentido de familia para lograr una integración activa en la sociedad que les permita un mejor desarrollo social. En sus expresiones, el amor y la simpatía canalizan este sentir ciudadano.

Sentido de vida: la significación, llenar de sentido las pequeñas cosas y simbolizar los sentires permiten un apego a la vida $\mathrm{y}$, por lo tanto, a la sociedad. Esta es para ellos una forma de construcción ciudadana que genera bienestar y armonía social. El potencial humano que se integra a la sociedad en unámbito de confianza y sentido de pertenencia puede ser contundente para el accionar ciudadano. Para estos jóvenes son de gran preocupación el suicidio, la drogadicción y la violencia, en cuanto comportamientos que deconstruyen y desmitifican el sentido de vida propia y el del otro y lo otro.

\section{Aproximaciones a las implicaciones de los imaginarios en el sentido de participación}

Como resultado de la aplicación del taller pedagógico, los estudiantes evidencian que sus actuales prácticas ciudadanas se encuentran estrechamente relacionadas con su emocionalidad política, es decir, que sus acciones están íntimamente relacionadas con lo que les proporciona amor, simpatía, miedo, odio, asco..., y que, por supuesto, son el reflejo del sentir profundo de sus imaginarios de ciudadanía. El respeto es para ellos determinante en la construcción y reconstrucción de los lazos de confianza con el otro, lo que quizá los motiva a la conexión con el sentir colectivo. De otro modo, la justicia incide profundamente en la movilización ciudadana. Si se cree en los estamentos gubernamentales y judiciales, tal vez se pueden dar procesos de participación social mucho más efectivos dados por la credibilidad y el reconocimiento de la verdad. Son muchos los escenarios de participación en los que se posibilita el ejercicio ciudadano, entre los que se encuentran espacios culturales para la sensibilización y las transformaciones, $y$ medios y elementos tecnológicos que contribuyen a la interacción y a la participación.

En el caso del maltrato animal, que se representa en el imaginario del respeto por lo otro, se producen movilizaciones sociales en estos espacios digitales. Igual ocurre cuando se dan casos de maltrato a los niños, a la mujer, de abuso sexual y toda clase de violencia. Los jóvenes se pronuncian a través de los diferentes espacios en la red, e incluso llegan a materializar sus acciones ciudadanas en el espacio físico. Otro caso de incidencia del 
imaginario se concreta cuando se producen críticas al mal ejercicio de la política y a los actos de corrupción. Rápidamente aparecen en los espacios digitales memes con mensajes de indignación, sarcasmo y hasta humor, denunciando y sancionando dichas prácticas. Este trabajo de investigación lleva a pensar que los jóvenes están atentos a las nuevas demandas sociales. Por eso, su sentido de participación se está dando desde sus motivaciones, desde esas nuevas formas en las que legitiman su ser y estar en la sociedad.

\section{Conclusiones}

Esta investigación permitió romper con estructuras y paradigmas que vinculan formas tradicionales de concebir la ciudadanía, permitiendo ver las subjetividades sociales actuales de los jóvenes estudiantes. Se logró entender la importancia de la emocionalidad política en los procesos de reconocimiento y construcción ciudadana, y que a través del amor, la simpatía, la aflicción, el miedo, la culpa, la ira, el asco y la envidia se logra un proceso comunicativo muy asertivo con los sentires sociales más profundos de los jóvenes estudiantes. Se pudo establecer que la ciudadanía trasciende múltiples escenarios sociales y que no está enmarcada dentro de una linealidad; que es dinámica y subjetiva y que cada vez integra nuevos elementos que demandan atención. Se logró reconocer que la emocionalidad política permite la denuncia social, el reclamo de los derechos, la aprobación o desaprobación del accionar del otro, el reconocimiento de los deberes, la resignificación de los vínculos sociales y la reflexión profunda sobre el papel que desempeñan los ciudadanos en la sociedad.
Se concluye que los imaginarios de ciudadanía en los jóvenes estudiantes inciden en sus procesos de participación social. En el caso de la corrupción y los sentimientos de rechazo y repulsión por estas prácticas, les genera desesperanza y los lleva en ocasiones al distanciamiento de los escenarios de participación. La falta de credibilidad y confianza en los sistemas de justicia no les permiten a los jóvenes muchas veces denunciar y reclamar por sus derechos. Con relación a los conceptos de política y democracia, sus sentires no son muy positivos, lo que los lleva al rechazo contundente de esto espacios. Ante el reconocimiento de las acciones de vulneración, violencia y deshumanización, sienten la necesidad de ser escuchados y algunos hacen uso de las redes sociales para denunciar y sancionar. En este sentido y relacionando los ejemplos mencionados, las maneras en las que se concibe la ciudadanía inciden en las dinámicas de participación y en los procesos de construcción ciudadana, y no necesariamente en un sentido negativo.

Esta investigación le aporta a la comunicación educativa pues se desarrolla en un contexto educativo que puede ser representativo para la población colombiana en general. En tal sentido, los resultados contribuyen al fortalecimiento de las prácticas pedagógicas en los escenarios universitarios. De otro modo, el proceso de diálogo con los sentires de los participantes vincula constante y directamente la comunicación. Se puede decir que esta cumple un papel de mediación entre la realidad social y los imaginarios de ciudadanía de los jóvenes universitarios, entendiendo además que la ciudadanía se constituye de procesos de interacción en todos los lenguajes. 
La relación entre estas dos grandes disciplinas, representada en la Maestría en Comunicación Educativa de la Universidad Tecnológica de Pereira, fortalecerá los procesos de investigación social, muy afines con este programa. De otro modo, la labor docente en el curso Proyecto de Vida de Uniminuto Sede Principal se verá enriquecida en las temáticas de carácter social y en el desarrollo de competencias ciudadanas, pues son temas fundamentales en este espacio de formación humana y social.

\section{Referencias}

Cárdenas, F. (2004). Caracterización estudiantes nuevos. Uniminuto Sede Principal. Bogotá.

Flores, J. (2009). Nuevos modelos de comunicación, perfiles y tendencias en las redes sociales. Comunicar, 33(17), pp. 73-81. Disponible en: https://www. revistacomunicar.com

Hernández, R., Fernández, C. \& Baptista, P. (2003). Metodología de la investigación. Canadá: McGraw-Hill. Disponible en: http://www.dgsc.go.cr/dgsc/documentos/ cecades/metodologia-de-la-investigacion. pdf

Nussbaum, M. (2014). Emociones Políticas, ¿por qué el amor es importante para la justicia? España: Espasa.

Prada, A. (2011). La formación del ciudadano en el siglo XXI. Una perspectiva universitaria. Revista de la universidad de la Salle. 61. Bogotá.

Silva, A. (2006). Imaginarios Urbanos. Colombia: Arango Editores.

Silva, A. (2012) Bogotá Imaginada. Colombia.

Toledo, U. (1998). Giambattista Vico y la Hermenéutica Social. Cinta de Moebio, 4, dic, Universidad de Chile.
Disponible en: http://www.redalyc.org/ pdf/101/10100403.pdf

Valles, M. (2007). Técnicas cualitativas de investigación social: reflexión metodológica y práctica profesional. Madrid, Síntesis.

Van Dijk, T. (1999). Análisis crítico del discurso (traducción de Manuel González de Ávila). Anthropos, 186, sep-oct, pp. 23-36. Disponible en: http://cisolog.com/ sociologia/teun-a-van-dijk-estudioscriticos-del-discurso/ 